\title{
Fixed drug eruption caused by tadalafil - Case report ${ }^{*}$
} Erupção fixa por droga provocada por tadalafil - Relato de Caso

\author{
Milan Bjekic ${ }^{1}$
}

Milica Markovic ${ }^{2}$

Sandra Sipetic ${ }^{3}$

DOI: http://dx.doi.org/10.1590/abd1806-4841.20131994

\begin{abstract}
Fixed drug eruptions (FDE) are commonly reported type of mucocutaneous drug eruption. The aim of this paper is to present a patient with multiple mucocutaneous erythema fixum type lesions caused by oral tadalafil use. A short course of topical corticosteroid therapy resulted in complete resolution of all lesions leaving residual hyperpigmentation of the involved skin sites. Mucosal oral lesions were effectively treated with gingival hyaluronic acid $0.2 \%$ gel. Conclusion: when assessing a patient of any age with drug eruptions, a thorough personal history should be obtained, in particular data on regular or recreational use of phospodiesterase type 5 inhibitors.
\end{abstract}

Keywords: Case reports; Dermatology; Drug eruptions

Resumo: A erupção fixa por droga é um tipo de erupção mucocutânea comumente relatada, provocada pela administração de de drogas. O objetivo deste artigo é apresentar um paciente com múltiplas lesões mucocutâneas do tipo do eritema fixo, causadas pelo uso do tadalafil oral. Um breve período de tratamento com corticosteroides tópicos levou à completa resolução de todas as lesões, deixando hiperpigmentação residual nas áreas cutâneas envolvidas. As lesões da mucosa oral foram tratadas efetivamente com gel de ácido hialurônico gengival a $0,2 \%$. Conclusão: ao avaliar o paciente com erupção fixa por druga, de qualquer idade, deve ser obtido seu histórico pessoal completo, especialmente dados sobre uso regular ou recreativo de inibidores de fosfodiesterase tipo 5 .

Palavras-chave: Dermatologia; Erupção por droga; Relatos de casos

\section{INTRODUCTION}

The fixed drug eruption (FDE) presents a commonly reported type of mucocutaneous drug eruption characterized by erythematous patches that develop within hours after ingestion of a drug. It usually recurs at the same site upon subsequent exposure to the same drug. ${ }^{1}$ The lesions may be solitary or multiple and may affect any part of the skin and mucosa; moreover, FDE frequently involves the genitalia. A large number of drugs have been reported to elicit fixed drug eruptions. ${ }^{2}$
In recent years drugs used for the treatment of erectile dysfunction have been increasingly prescribed for men; however, phospodiesterase type 5 inhibitors (PDE5i) gained popularity even among men without erectile dysfunction to enhance sexual performance satisfaction. $^{3}$

Herein we report a rare case of tadalafilinduced fixed drug eruption in a 30-year old man who used it as a recreational drug.

\footnotetext{
Received on 18.07.2012.

Approved by the Advisory Board and accepted for publication on 14.08.2012.

* Work conducted at City Institute for Skin and Venereal Diseases - Belgrade, Serbia.

Financial Support: This work is supported by the Ministry for Science and Technology of Serbia, through Contract No.175042 (2011-2014)

Conflict of Interests: None.

PhD - Head of venereological department, City Institute for Skin and Venereal Diseases - Belgrade, Serbia.

Specialist - Dermatovenereologist, City Institute for Skin and Venereal Diseases - Belgrade, Serbia.

PhD - Professor of Epidemiology, Institute of Epidemiology, School of Medicine, Belgrade University - Belgrade, Serbia.

(C)2013 by Anais Brasileiros de Dermatologia
} 


\section{CASE REPORT}

A 30-year old man referred to City Institute for Skin and Venereal Diseases complaining of recurrent red spots on the skin and genitalia. They appeared on the same skin sites and resolved three times consecutively during 6 months. The subjective symptom was only mild pruritus. Physical examination during the first visit revealed a solitary erythematous patch, $2 \mathrm{~cm}$ in diameter, on the penile shaft. Treatment with topical corticosteroid cream resulted in complete resolution of the lesion in a few days. Apart from the clinically suggestive patch, at first visit the diagnosis of erythema fixum could not be complemented with the appropriate anamnestic data since the patient denied oral ingestion of any drug preceding the onset of the lesion. He was advised to carefully look for skin and genital lesions if using oral antibiotics or nonsteroid anti-inflammatory drugs. The next episode of disseminated patches developed suddenly on the penis, right forearm and left periorbital region, nevertheless the patient did not come to the clinic for examination. Instead, he applied topical corticosteroid cream on his own, for a couple of days. Few weeks after the complete resolution of all patches they reappeared on identical sites of the skin, with one new lesion on the buccal mucosa. Upon referral, the third episode clinically presented with multiple erythematous violaceous disseminated patches on the penile shaft, right elbow, left periorbital region as well as patches and erosions on buccal mucosa and hard palate (Figures 1, 2 and 3). The patient was worried and motivated for cooperation so his thorough medical history revealed that each episode was elicited by the same event recreational use of tadalafil for enhancement of coital excitement and pleasure, approximately once every 3 months during the previous year. The patient denied any other concurrent symptoms and diseases; complete blood count, biochemical parameters, serum aminotransferase values and urine analysis were all within normal physiological ranges.

A short course of topical corticosteroid therapy once again resulted in complete resolution of all lesions leaving residual hyperpigmentation of the involved skin sites. Mucosal oral lesions were effectively treated with gingival hyaluronic acid $0.2 \%$ gel.

\section{DISCUSSION}

Fixed drug eruptions (erythema fixum) are a distinctive variant of drug induced dermatosis with characteristic recurrence at the same skin and/or mucosal sites after repeated administration of the same drug. Sites of predilection include: lips, extremities and genitalia; lesions are sharply demarcated, round to oval measuring several centimeters in diameter. Erythema fixum presents as solitary or multiple

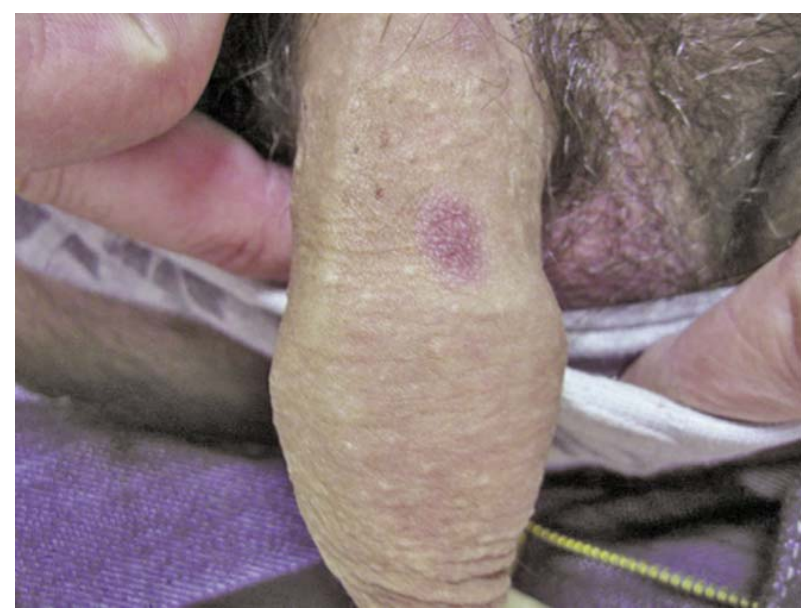

Figure 1: Penile lesion of erythema fixum

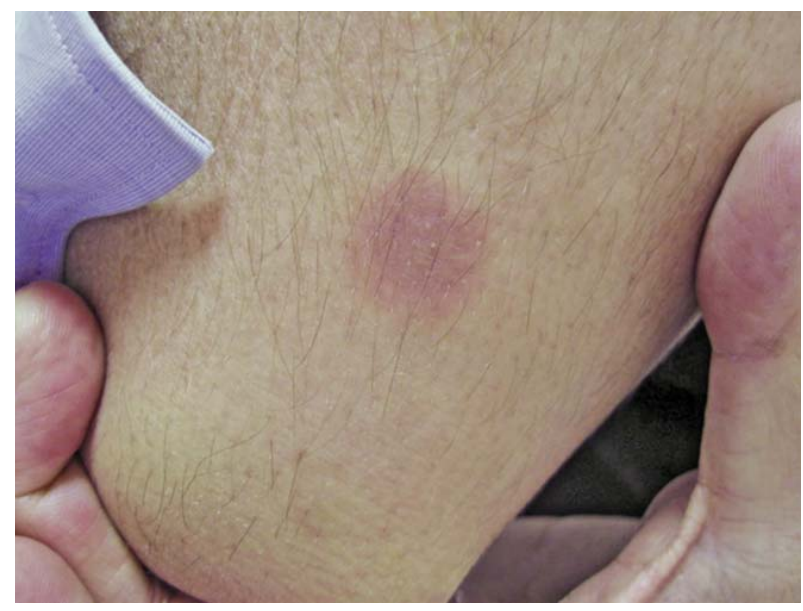

FIGURE 2: Erythema fixum on the elbow

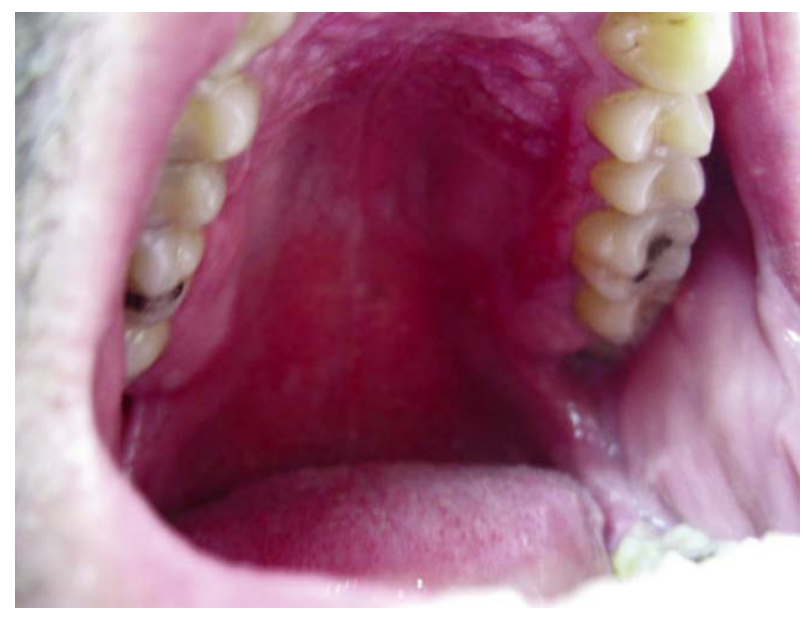

Figure 3: Mucosal patch of fixed erythema 
patches, usually localized, however repeated episodes might have increased the number and size of the lesions, as described in the case presented herein. Pruritus and burning sensation may well be associated symptoms. ${ }^{1}$

Fixed drug eruption may be elicited by various drugs, however the most frequently implicated medications are antibiotics (especially trimethoprim-sulfamethoxazole) followed by nonsteroidal anti-inflammatory drugs. ${ }^{4}$

The current epidemiological literature on erectile dysfunction suggests that approximately $5-20 \%$ of men have moderate-to-severe ED. ${ }^{5}$ Oral inhibitors of phosphodiesterase type 5 are considered first-line therapies for ED. One of them, tadalafil, has demonstrated significant improvement of erectile function for up to 36 hours after dosing, and is well tolerated, less then $5 \%$ of the patients discontinue the use because of adverse effects. ${ }^{6}$ In the study of Bechara et $a l .{ }^{3}, 21.5 \%$ of healthy men between 18 and 30 years old used PDE5i as a recreational drug, mostly associated with alcohol or other drugs; our patient belongs to the above mentioned age group and was also a recreational tadalafil user with no known erectile dysfunction. To the best of our knowledge, a literature review regarding drugs used for treatment of erectile dysfunction reveals only one reported case of FDE caused by tadalafil. ${ }^{7}$ Beach et al. described a recurrent circleshaped lesion on the penis of a 56-year old man who repeatedly used tadalafil. In our case, multiple patches including penile lesion, extremities and oral mucosa involvement have been observed.

To confirm the diagnosis of FDE different skin tests including patch, prick and oral challenge test with suspected drugs may be performed. ${ }^{8}$ However, the diagnosis itself usually relies on typical clinical manifestation of lesion(s), the course of recurrent attacks preceded by the use of same drug.

The first line treatment for FDE is prevention of attacks and recurrences, which is done simply by avoiding the offended drug if possible. Discontinuation of the drug itself is usually the only necessary treatment; in addition, topical corticosteroids might as well be effective in lesion regression.

To our knowledge this is the second case reported in the literature which describes fixed drug eruption elicited by tadalafil use. Having in mind the increase of recreational use of tadalafil and other PDE5i-s, the anamnestic procedure in patients with suspected drug reaction should include questions regarding use of erectile dysfunction drugs. The data on regular or recreational use of PDE5i-s and tadalafil in particular should not be missed when assessing patients of any age with drug eruptions.

\section{REFERENCES}

1. Lee AY. Fixed drug eruptions. Incidence, recognition, and avoidance. Am J Clin Dermatol. 2000;1:277-85.

2. Gendemalik SB, Galeckas KJ. Fixed drug eruptions: a case report and review of the literature. Cutis. 2009;84:215-9.

3. Bechara A, Casabe A, De Bonis W, Helien A, Bertolino MV. Recreational use of phosphodiesterase type 5 inhibitors by healthy young men. J Sex Med. 2010;7:3736-42.

4. Mahboob A, Haroon TS. Drugs causing fixed eruptions: a study of 450 cases. Int J Dermatol. 1998;37:833-8.

5. Kubin M, Wagner G, Fugl-Meyer AR. Epidemiology of erectile dysfunction. Int $\mathrm{J}$ Impot Res. 2003;15:63-71

6. Young JM, Feldman RA, Auerbach SM, Kaufman JM, Garcia CS, Shen W, et al. Tadalafil improved erectile function at twenty-four and thirty-six hours after dosing in men with erectile dysfunction: US trial. J Androl. 2005;26:310-8.

7. Beach RA, Murphy F, Vender RB. Cutaneous reaction to drugs for erectile dysfunction: case report and review of the literature. J Cutan Med Surg. 2006;10:128-30.

8. Kim KJ, Jeong MC, Yoo JH. Clinical study and skin tests of patients with drug eruption. Korean J Dermatol. 1998;36:887-896.

\author{
MAILING ADDRESS: \\ Milica Markovic \\ Dzordza Vasingtona, 17 \\ 11000 - Belgrade - Serbia \\ E-mail:mipopovi@eunet.rs
}

How to cite this article: Bjekic M, Markovic M, Sipetic S. Fixed drug eruption caused by tadalafil - Case report. An Bras Dermatol. 2013;88(4):617-9. 